\title{
Peroxynitrite-Mediated Protein Nitration and Lipid Peroxidation in a Mouse Model of Traumatic Brain Injury
}

\author{
EDWARD D. HALL, ${ }^{1}$ MEGAN R. DETLOFF, ${ }^{2}$ KJELL JOHNSON, ${ }^{2}$ and NANCY C. KUPINA ${ }^{2}$
}

\begin{abstract}
The role of reactive oxygen-induced oxidative damage to lipids (i.e., lipid peroxidation, LP) and proteins has been strongly supported in previous work. Most notably, a number of free radical scavengers and lipid antioxidants have been demonstated to be neuroprotective in traumatic brain injury (TBI) models. However, the specific sources of reactive oxygen species (ROS), the time course of oxidative damage and its relationship to post-traumatic neurodegeneration in the injured brain have been incompletely defined. The present study was directed at an investigation of the role of the ROS, peroxynitrite (PON), in the acute pathophysiology of TBI and its temporal relationship to neurodegeneration in the context of the mouse model of diffuse head injury model. Male CF-1 mice were subjected to a moderately severe head injury and assessed at 1-, 3-, 6-, 12-, 24-, 48-, 72, 96and 120-h post-injury for neurodegeneration using quantitative image analysis of silver staining and semi-quantitative analysis of PON-mediated oxidative damage to proteins (3-nitrotyrosine, 3-NT) and lipids (4-hydroxynonenal, 4-HNE). Significant evidence of silver staining was not apparent until 24-h post-injury, with peak staining seen between 72 - and $120-\mathrm{h}$. This time-course of neurodegeneration was preceded by intense immunostaining for 3-NT and 4-HNE, which occurred within the first hour post-injury. The time course and staining pattern for 3-NT and 4-HNE were similar, with the highest staining intensity noted within the first $48-\mathrm{h}$ in areas surrounding trauma-induced contusions. In the case of 3-NT, neuronal perikarya and processes and microvessels displayed staining. The temporal and spatial coincidence of protein nitration and LP damage suggests that PON is involved in both. However, lipid-peroxidative (4-HNE) immunoreactivity was broader and more diffuse than 3-NT, suggesting that other reactive oxygen mechanisms, such as iron-dependent LP, may also contribute to the more widespread 4-HNE immunoreactivity. This indicates that optimal pharmacological inhibition of post-traumatic oxidative damage in TBI may need to combine two functionalities: one to scavenge PON or PON-derived radicals, and the second to inhibit LP caused by multiple ROS species.
\end{abstract}

Key words: neurodegeneration; oxidative damage; reactive oxygen species; traumatic brain injury

${ }^{1}$ Spinal Cord and Brain Injury Research Center, University of Kentucky Chandler Medical Center, Lexington, Kentucky.

${ }^{2}$ CNS Pharmacology, Pfizer Global Research and Development, Ann Arbor, Michigan. 


\section{INTRODUCTION}

$\mathbf{T}$ HERE IS NOW compelling support for an important role of reactive oxygen species (ROS) in the pathophysiology of acute TBI (Hall and Braughler, 1993; Hall, 1995a). Pioneering work by Kontos and colleagues demonstrated an almost immediate post-injury increase in brain microvascular superoxide radical production, associated with a compromise of autoregulatory function in fluid percussion TBI models. As well, scavengers of superoxide radical $\left(\mathrm{O}_{2}{ }^{-}\right)$have been shown to reduce post-traumatic superoxide levels and protect against the loss of autoregulatory competency (Kontos and Povlishock, 1986; Kontos and Wei, 1986). Through the use of salicylate trapping, rising levels of brain hydroxyl radical $(\cdot \mathrm{OH})$ have been documented in mouse diffuse and rat focal TBI models (Hall and Braughler, 1993; Hall et al., 1994; Hall and Braughler, 1993; Smith et al., 1994; Globus et al., 1995). As with the work of Kontos, the cerebral microvasculature appears to be the initial site of post-traumatic radical production. More recent work indicates that increased ROS leakage from damaged mitochondria in the brain (Azbill et al., 1997; Matsushita and Xiong, 1997; Sullivan et al., 1999a; Sullivan et al., 1999b) or spinal cord (Azbill et al., 1997) is a major source of trauma-induced radical production.

ROS-induced lipid peroxidation (LP) is the most studied mechanism of oxidative damage in models of TBI. For example, through the use of a rat focal contusion model, Smith and colleagues demonstrated an increase in brain LP products (lipid hydroperoxides) that is measurable within 30 min post-injury. The LP increase followed closely behind the increase in $\cdot \mathrm{OH}$ (Smith et al., 1994). Moreover, on the heels of the increased LP products, there is an opening of the blood-brain barrier (BBB) suggesting that the initial site of ROS-induced LP is the microvascular endothelium. Consistent with this hypothesis, the 21-aminosteroid LP inhibitor tirilazad, which has high affinity for cerebrovascular endothelium (Hall et al., 1994), has been shown to attenuate post-traumatic BBB opening (Hall et al., 1992; Smith et al., 1994). Later work confirmed the post-traumatic increase in LP products in rats after focal contusion injury and its association with brain edema mechanisms (Nishio et al., 1997).

Several studies, using multiple TBI models, have demonstrated that the LP inhibitor tirilazad is a potent neuroprotective agent (Hall et al., 1994). In addition, several other radical scavengers and LP inhibitors have been reported to be effective neuroprotectants in TBI models, including the vitamin E analog U-78517F (Hall, 1995b); the pyrrolopyrimidine U-101033E (Hall, 1997) and the spintrapping agents $\alpha$-phenyl-tert-butylnitrone (PBN) (Awasthi et al., 1997; Marklund et al., 2001) and OPC-14117 (Mori et al., 1998). Transgenic animals that over-express the antioxidant enzymes $\mathrm{Cu} / \mathrm{Zn}$ or $\mathrm{Mn}$ superoxide dismutase also display less post-traumatic brain damage than in wild-type mice (Chan et al., 1995; Mikawa et al., 1996). The clinical relevance of ROS biochemistry is supported by the recent demonstration that TBI patients with brain contusions display increases in LP products in erythrocytes and CSF at 2-8 days post-injury (Kasprzak et al., 2001). Furthermore, treatment with tirilazad is capable of reducing mortality in severely injured patients with traumatic subarachnoid hemorrhage (Marshall et al., 1998). Thus, ROS-induced LP and the therapeutic potential of antioxidant drugs as neuroprotective agents is, perhaps, one of the best (albeit incompletely) validated approaches to treat acute TBI.

A principal mechanism of ROS formation and damage has been shown to involve iron, particularly in the ferrous $\left(\mathrm{Fe}^{2+}\right)$ form. Iron, released from iron storage proteins (hemoglobin, ferritin, transferrin), can react with hydrogen peroxide $\left(\mathrm{H}_{2} \mathrm{O}_{2}\right)$ leading to the formation of the highly reactive hydroxyl radical $(\cdot \mathrm{OH})$ (i.e., Fenton reaction). Hydroxyl radicals are potent initiators of peroxidative damage to polyunsaturated fatty acids (Hall and Braughler, 1993). However, about 12 years ago, Beckman and coworkers introduced the theory that the principal ROS involved in producing tissue injury in a variety of neurological disorders is peroxynitrite (PON; $\left.\mathrm{ONOO}^{-}\right)$, formed by the reaction of nitric oxide synthase (NOS)-generated $\cdot \mathrm{NO}$ radical and $\mathrm{O}_{2}{ }^{-}$(Beckman, 1991; Beckman et al., 1993). Since that time, the biochemistry of PON (often referred to as a reactive nitrogen species) has been further clarified. PON-mediated oxidative damage is actually caused by PON decomposition products that possess potent free radical characteristics. These products are formed in one of two ways. The first involves the protonation of $\mathrm{PON}$ to form peroxynitrous acid (ONOOH), which can undergo homolytic decomposition to form the highly reactive nitrogen dioxide radical $\left(\cdot \mathrm{NO}_{2}\right)$ and $\cdot \mathrm{OH}$. Probably more physiologically important, PON will react with carbon dioxide $\left(\mathrm{CO}_{2}\right)$ to form nitrosoperoxocarbonate $\left(\mathrm{ONOOCO}_{2}\right)$, which can decompose into $\cdot \mathrm{NO}_{2}$ and carbonate radical $\left(\cdot \mathrm{CO}_{3}\right)$.

Each of the PON-derived radicals $\left(\cdot \mathrm{OH}, \cdot \mathrm{NO}_{2}\right.$, and $\cdot \mathrm{CO}_{3}$ ) can initiate LP cellular damage by the abstraction of an electron from a hydrogen atom bound to an allylic carbon in polyunsaturated fatty acids or cause protein carbonylation by reaction with susceptible amino acids (e.g., lysine, cysteine, arginine). Moreover, the aldehydic LP products malondialdehyde (MDA) and 4-hydroxynonenal (4-HNE) can bind to cellular proteins compromising their structural and functional integrity. 4-HNE is the more interesting of the two aldehydes in that it is actually neurotoxic (Kruman et al., 1997). Additionally, $\cdot \mathrm{NO}_{2}$ can nitrate the 3 position of tyrosine residues in proteins; 
3-nitrotyrosine (3-NT) is a specific biomarker of PONinduced cellular damage. These oxidative mechanisms undoubtedlyunderly the demonstrated neurodegenerative effects of PON shown by several investigators in neuronal cell culture models (Kruman et al., 1997; Neely et al., 1999).

The present study was undertaken in a mouse model of diffuse TBI to examine by immunohistochemistry the temporal and spatial characteristics of protein nitration and LP using 3-NT and 4-HNE as respective markers. The first hypothesis to be tested was that both oxidative markers would occur simultaneously implying that they were initiated by a common ROS species, namely PON. The second hypothesis to be tested was that these oxidative damage indices precede the timing of neurodegeneration. Accordingly, the time course of protein nitration and lipid peroxidative damage was compared to the time course of silver staining in order to determine the temporal relationship of oxidative damage mechanisms to post-traumatic neurodegeneration.

\section{MATERIALS AND METHODS}

\section{Subjects}

The present studies were conducted in adult male CF-1 mice (Charles River, Portage, MI) weighing 29-32 g. All injury procedures were performed under isoflurane anesthesia and were approved by the Pfizer Global Research \& Development Institutional Animal Care and Use Committee (Ann Arbor Laboratories). Tissues were harvested for histochemistry and immunohistochemistry using deep pentobarbital anesthesia.

\section{Mouse Model of Diffuse Closed Head Injury}

The mouse model of diffuse head-injury was employed as described (Hall, 1995b) with recent minor modifications (Kupina et al., 2001, 2002, 2003). Male CF-1 mice weighing 29-32 g (6-8 weeks old) were fed and watered ad libitum prior to injury. At the time of injury, each mouse was anesthetized in a Plexiglas chamber contain-

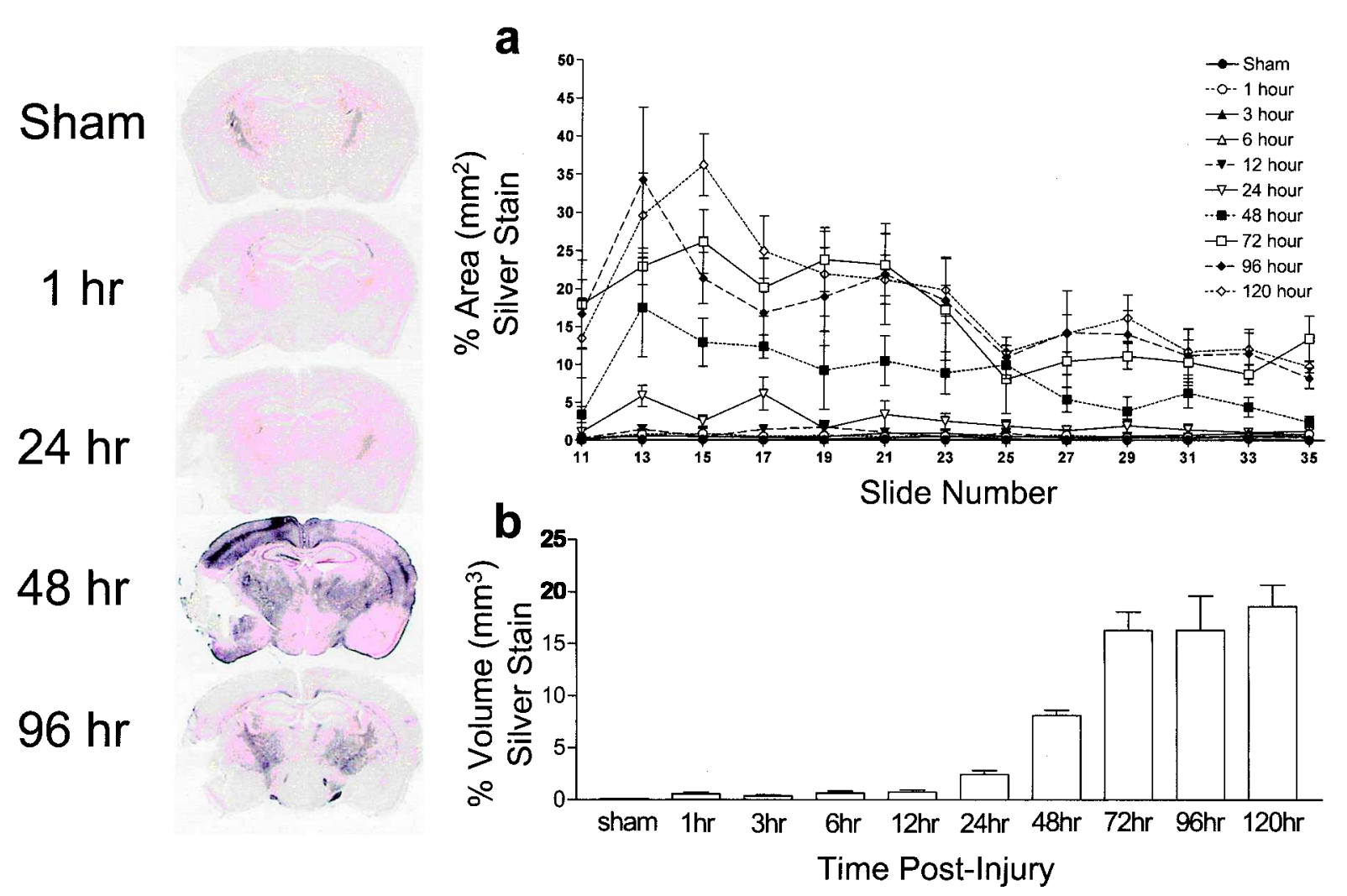

FIG. 1. Time course of post-traumatic neurodegeneration, as assessed by area and volumetric measurement of silver staining (deOlmos, 1994), via quantitative image analysis (Kupina et al., 2002, 2003). The top panel (a) shows an anterior $\rightarrow$ posterior distribution of staining in units of $\%$ area of staining in different brain sections. The bottom panel (b) graphically displays the $\%$ volume of silver staining. Very little staining is apparent within the first $12 \mathrm{~h}$ post-injury. The $\%$ volume of neurodegeneration is seen to increase at $24 \mathrm{~h}$; however, the peak of neurodegenerationdoesn't occur until $72 \mathrm{~h}$ after injury and persists until, at least, $120 \mathrm{~h}$ (values $=$ mean \pm SEM for $n=5$ at each time point). Typical examples of post-traumatic silver staining at $1,24,48$, and $96 \mathrm{~h}$ post-injury are shown on the left (sections are counter-stained with neutral red). 
ing $2.5 \%$ isoflurane (Anaquest) and then grasped by the dorsal skin of the neck and its head placed firmly upon the metal base of the injury device. A round, flat, 6-mm diameter Teflon impounder was positioned firmly against the top of the head, centered between the ears and eyes (encompassing the area over the frontal and parietal bones) and a 100-g stainless steel weight released at a height of $10.5 \mathrm{~cm}$. This injury is characterized as moderately severe and results in a $20 \%$ mortality during the first 5 min post-injury. In survivors, the resulting injury creates a pattern of diffuse degeneration, which peaks at $72 \mathrm{~h}$ (Kupina et al., 2003). In order to prevent immediate post-traumatic hypothermia, injured mice were placed in a Hova-Bator incubator (model 1583, Randall Burkey Co.) set at $37^{\circ} \mathrm{C}$ until consciousness (return of righting reflex and mobility) was regained (20-30 $\mathrm{min})$. In a previous study (Kupina et al., 2001), rectal temperatures taken 2-h following injury indicated TBI male mice to be approximately $2^{\circ} \mathrm{C}$ cooler than sham-injured mice $\left(35.4 \pm 0.3^{\circ} \mathrm{C}\right.$ vs. $37.7 \pm 0.1^{\circ} \mathrm{C}$, mean $\left.\pm \mathrm{SE}\right)$. By 24 and 48 -h post-injury, TBI mice remain about $1^{\circ} \mathrm{C}$ cooler compared to sham-injured mice $\left(36.9 \pm 0.2^{\circ} \mathrm{C}\right.$ vs. $38.0 \pm$ $0.2^{\circ} \mathrm{C}$, mean $\pm \mathrm{SE}$ ).

\section{Quantification of Neuronal Degeneration by Silver Staining}

Neurodegeneration in injured brains was detected by the de Olmos amino cupric silver histochemical technique as previously described (Grafe and Leonard, 1980; Yamamoto et al., 1986; de Olmos et al., 1994; Switzer, 2000; Kupina et al., 2002; Kupina et al., 2003). At the intended time of sacrifice, the mice were deeply anesthetized with pentobarbital (200 mg/kg I.P.) and transcardially perfused with $0.9 \%$ sodium chloride and then with a fixative solution containing $4 \%$ paraformaldehyde, $4 \%$ sucrose, and $0.01 \mathrm{M}$ sodium cacodylate. Following decapitation, the heads were stored in fixative for $24 \mathrm{~h}$, after which the brains were removed, placed in fresh fixative and shipped $\left(4^{\circ} \mathrm{C}\right)$ for histological processing (Neuroscience Associates, Inc., Knoxville, TN). Brains were embedded into blocks of gelatin (maximum of 25 brains/block). Frozen sections were cut coronally, at a thickness of $35 \mu \mathrm{m}$, silver stained for neuronal degeneration and counter-stained with Neutral Red to reveal neuronal cell bodies.

Thirteen equidistant sections from each of the blocks were used for analysis of silver staining. Brain sections were photographed under a $1 \times$ objective lens and imported, calibrated (using a slide micrometer) and saved into the computer software program SigmaScan Pro 5 (SPSS, Inc., Chicago, IL). Utilizing a pre-programmed software method of contrast-enhancement and densitometric thresholding, the percentage area of silver stain- ing in each brain section was calculated by dividing the area of silver staining in each section by the area of the total brain section and multiplying by 100 . The densitometric thresholding of each tissue section was completed by a blinded observer who visually compared each captured computer image with the matching microscope slide. Densitometric thresholding, beyond background noise, was not included. In an instance of unavoidable inclusion of background noise, care was taken to include the same elements in the thresholding of the total brain section, thereby discounting the noise in the final calculation of the section's total area of silver staining. Percent measurements were used to compensate for differences in brain size between animals. Percent volume of silver staining was estimated by the equation $\% \mathrm{~V}=\mathrm{t} *$ $\Sigma \%$ a (s), where $\% \mathrm{~V}$ is percent silver stain volume, $\mathrm{t}$ is the distance between sections analyzed $(420 \mu \mathrm{M})$ and $\Sigma$ $\% \mathrm{a}(\mathrm{s})$ is the sum of percent area of silver staining in all sections examined (13 for each brain).

\section{Immunohistochemistry}

Alternate sections were used for immunohistochemistry of oxidative damage markers. 3-Nitrotyrosine immunostaining was examined as first described by (Beckman et al., 1993) using a polyclonal rabbit antibody from Upstate Biotechnology (Charlottesville, VA) (cat. no. 20-107). The concentration of the primary antibody was 1:1500. 4-Hydroxynonenal immunostaining was carried out as first described by (Uchida and Stadtman, 1993) using a polyclonal rabbit antibody from Calbiochem (La Jolla, CA) (cat. no. 393205). The employed concentration was 1:5000. For both immunostains, the DAKO Envison Kit (Carpenteria, CA) was employed which uses a goat anti-rabbit IgG secondary antibody.

\section{RESULTS}

\section{Time Course of Neurodegeneration}

Figure 1 displays the time course of neurodegeneration after moderately-severe diffuse TBI in male CF-1 mice quantified by image analysis of silver stained sections. This study mimics an earlier study which examined the post-traumatic time course in the currently employed model (Kupina et al., 2003), with the exception of a broader investigation of earlier and later time points post-TBI in the present instance. As shown in Figure 1a, $\mathrm{b}$, only a small amount of silver staining is apparent prior to $24 \mathrm{~h}$ post-injury. However, between 24 and $72 \mathrm{~h}$, a progressive increase in neurodegeneration is observed that peaks and plateaus between 72 and $120 \mathrm{~h}$. In anterior brain sections, the area of neurodegeneration is as 


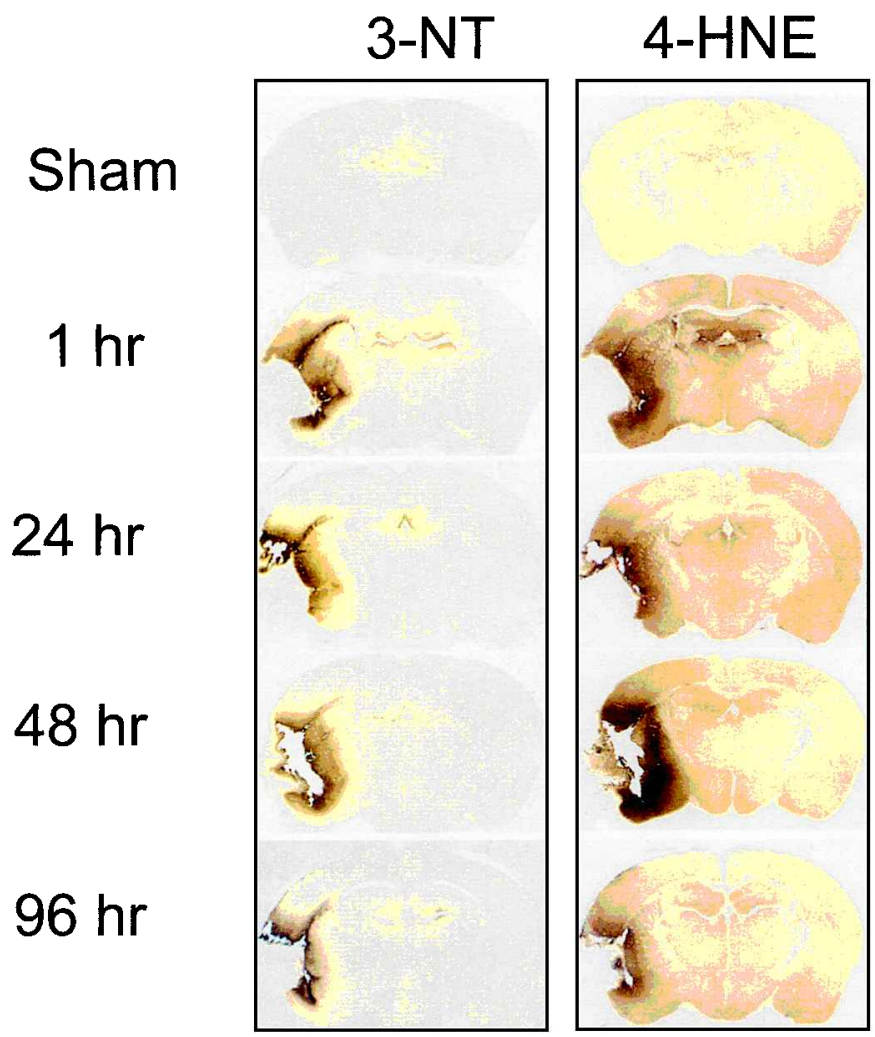

\section{$-1^{\circ} \mathrm{Ab}$ control}

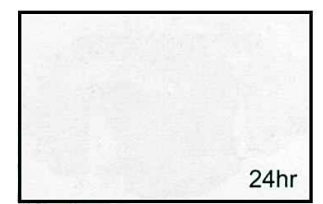

FIG. 2. Examples of 3-NT and 4-HNE in injured mouse brains at different times after moderately severe diffuse TBI. Each pair of examples (adjacent sections, stained for 3-NT and 4-HNE, at each time point) shows a $90^{\circ}$ (i.e., lateral) contusion that is intensely co-stained for both 3-NT and 4-HNE. These contusions occur in about a third of the mice subjected to this particular injury force (Kupina et al., 2003). The staining for both parameters is observed as early as $1 \mathrm{~h}$ postinjury, and persists out to $96 \mathrm{~h}$. The staining for 4-HNE is seen to extend much more diffusely beyond the peri-contusion area in comparison to the 3-NT staining. Therefore, the distribution of lipid peroxidative damage may be greater than for protein nitrative damage. In the sham (non-injured) animals, greater 4-HNE staining is also apparent in comparison to very limited 3-NT immunoreactivity. Control sections ( $24 \mathrm{~h}$ postinjury brain for 3-NT and $48 \mathrm{~h}$ post-injury brain for 4-HNE), which were not exposed to the primary antibody, show the specificity for the immunostains.

\section{3-NT Staining}

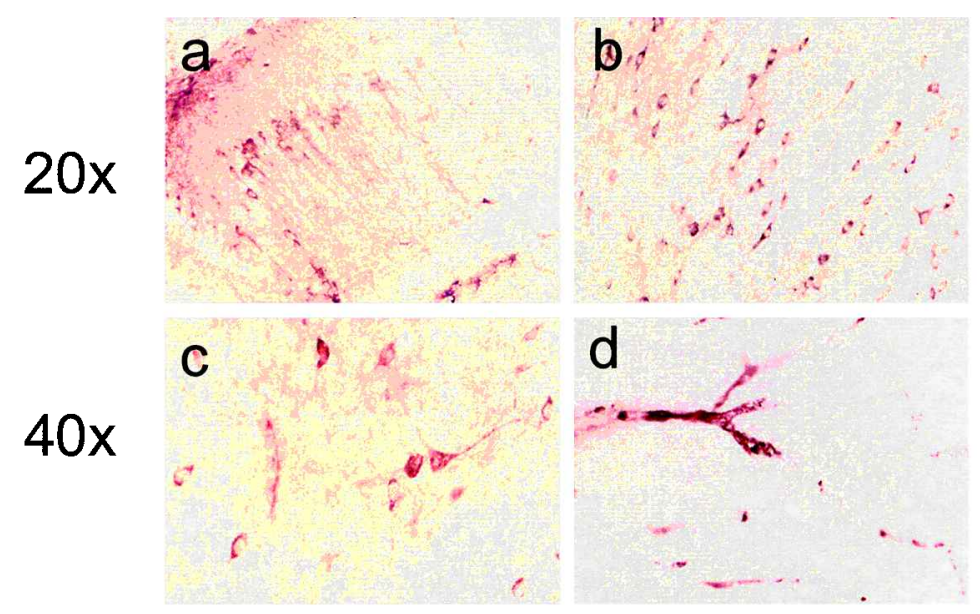

FIG. 3. High power examples of 3-NT immunostaining in a 1-h post-injury brain showing that 3-NT is localized in neuronal cell bodies and axonal/dendritic processes $(\mathbf{a}-\mathbf{c})$ and in microvessels $(\mathbf{d})$. 
high as $35 \%$ (Fig. 1a). The peak volume of neurodegeneration in the forebrain is approximately $20 \%$ (Fig. 1b). Histological examples are shown on the left of the figure illustrating the finding that a dramatic increase in silver staining occurs between 24 and $48 \mathrm{~h}$ after injury. It should be noted that in each of the post-injury examples, a large lateral (gliding) contusion is apparent. These contusions are present in approximately a third of the mice following the presently employed injury force (Kupina, et al., 2003).

\section{Time Course of Injury Due to Protein Nitration and Lipid Peroxidation}

A rapid post-traumatic increase in immunohistochemical markers of oxidative damage was observed. As shown in Figure 2, intense immunostaining was apparent for both 3-NT and 4-HNE as early as $1 \mathrm{~h}$ after injury. Both stains were particularly intense in the peri-contusion areas at each of the examined time points. In the case, of 4-HNE, the staining was more diffuse than that seen for 3-NT. Even in sham (non-injured) brains, there was much more evidence of diffuse 4-HNE modification of brain proteins. However, the intensity of the diffuse 4-HNE staining was clearly increased between 1 and $24 \mathrm{~h}$ post-injury and persisted out to $96 \mathrm{~h}$. 3-Nitrotyrosine staining was observed in both neurons (Fig. 3a-c) and microvascular endothelium(Fig. 3d), as also reported by others (Mesenge et al., 1998a). In the case of neurons, rich staining was apparent throughout the cytoplasm of both cell bodies and the proximal portions of axonal and dendritic processes. Although neurons also displayed considerable 4-HNE staining, evidence of this lipid peroxidative marker was seen throughout the neuropil, suggesting that it may also be present in glial and microvascular cell types (Fig. 4).

To assess the degree of oxidative damage in the injured brains, a semi-quantitative grading scale was devised to measure the degree of immunoreactivity for 3NT and 4-HNE (Fig. 5). For both 3-NT and 4-HNE, a score of $1=$ minimal staining equivalent to that seen in sham, non-injured brains; a score of 5 represented maximally intense staining. Using this scale, the 3-NT and 4HNE stained sections at the level of the dorsal hippocampus were blindly graded at each of the post-injury time points. As shown in Figure 6, protein nitration and LP immunoreactivity increased to a peak level within the first hour and remained at that intensity level through $48 \mathrm{~h}$ post-injury. Between 48 and $96 \mathrm{~h}$, the mean staining intensity for both 3-NT and 4-HNE progressively declined. However, even at $96 \mathrm{~h}$ post-injury, both markers were still elevated above the level seen in sham, non-injured. It is apparent, when comparing the overall time course of 3-NT and 4-HNE with silver staining (Fig. 1), that the peak damage caused by protein nitration and LP precedes the timing of maximal neuronal damage. However, oxidative damage markers persist throughout the time course of neurodegeneration.

\section{DISCUSSION}

The present results have, for the first time, defined the time course of oxidative injury versus the time course of neurodegeneration in a model of diffuse TBI. Damage caused by protein nitration and lipid peroxidation develops rapidly, preceding neurodegeneration, and persists throughout the time of peak neurodegeneration. 3-Nitrotyrosine and 4-HNE staining are particularly intense in areas adjacent to brain contusions and in those areas, the 3-NT and 4-HNE staining are spatially and temporally coincident. Both neurons and the cerebral microvasculature show oxidative damage suggesting that the initiator of the damage is generated in both contexts. Since 3-NT is a selective biomarker of PON (Beckman, 1991; Beckman et al., 1993), it is most likely that PON is the reactive oxygen (nitrogen) species that is responsible. Moreover, the linkage between PON and post-traumatic neurodegeneration is supported by the recent findings that PON, generated in the injured rat spinal cord, induces apoptotic neuronal death and activation of caspase 3 (Bao and Liu, 2003).

The implications of PON in post-traumatic pathophysiology are further derived from four lines of evidence. First, all three NOS isoforms (endothelial [eNOS], neuronal [nNOS], and inducible [iNOS]) are known to be up-regulated, in rodents, during the first $24 \mathrm{~h}$ following TBI (Cobbs et al., 1997; Rao et al., 1999; Gahm et al., 2000). One study looked at the time course of the individual NOS isoforms after focal contusion in the rat and found that eNOS peaked at $6 \mathrm{~h}$, while iNOS and nNOS did not peak until $12 \mathrm{~h}$ post-injury (Gahm et al., 2000). However, in a more diffuse TBI model (rat impact-acceleration), the upregulation of iNOS was not detected until $24 \mathrm{~h}$ post-TBI (Petrov et al., 2000) In this same model, nNOS activity was increased as early as $3 \mathrm{~h}$ post-injury (Park and Yi, 2001). Induction of iNOS has also been documented in contused human brain tissue as early as $6 \mathrm{~h}$ post-injury, with a peak between 8 and $23 \mathrm{~h}$ (Gahm et al., 2002). In another study (Orihara et al., 2001), an increase was not seen until $48 \mathrm{~h}$ post-injury. In human post-mortem studies, magnetic resonance spectroscopy has also been used to observe an apparent increase in the NOS byproduct, citrulline, following TBI (Silberstein et al., 2002). The results of all of these studies would indi- 


\section{4-HNE Staining}

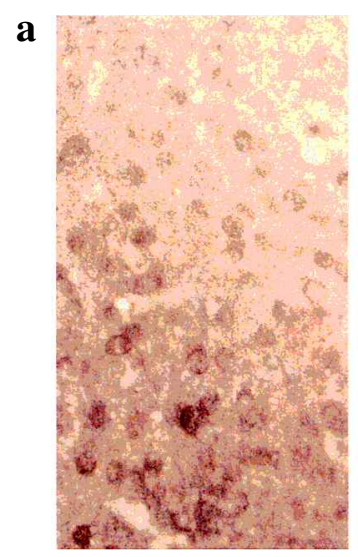

$20 x$

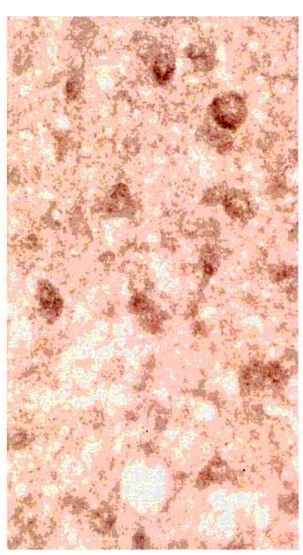

$40 x$
FIG. 4. High-power examples of 4-HNE immunostaining in cortical neurons. (a) Extensive cytoplasmic staining, which is even more apparent at higher power (b). The immunoreactivity is more diffuse than that seen in Figure 3 for 3-NT, suggesting that it may involve neuronal, glial and microvascular cell types.

cate that the timing of NOS induction is heavily dependent on the nature of the TBI.

Secondly, multiple laboratories have shown that the acute treatment of injured mice or rats with NOS inhibitors can exert a neuroprotective effect and/or improve neurological recovery (Mesenge et al., 1996; Wallis et al., 1996; Wada, 1999; Mesenge et al., 1998a; Wada et al., 1998a,b, 1999), consistent with the concept that NOS induction after TBI is pathophysiologically important. Most of these studies have looked at non-selective NOS inhibitors, such as L-nitroarginine methyl ester (LNAME) (Mesenge et al., 1996, 1998a; Wada et al., 1999), which does not allow for a determination of which NOS isoforms are most important in acute TBI pathophysiology. However, selective inhibitors of nNOS, such as 7-nitroindazole (Mesenge et al., 1996; Wada et al., 1998a,b), or iNOS, such as aminoguanidine (Wada et al., 1998b), have also been found to be effective in TBI models. It is most likely that all of the NOS isoforms (eNOS, nNOS and iNOS) contribute $\mathrm{NO}$ to the formation of PON at different stages after injury.

Thirdly, in addition to the present results, biochemical markers of PON-mediated damage have previously been documented in rodent TBI paradigms, including an increase in 3-NT levels (Mesenge et al., 1998a,b) and ADP ribosylation (evidence of poly ADP ribose polymerase, PARP, activation). The notion that these markers of PON-mediated damage are pathophysiologically impor- tant is supported by the finding that the non-selective NOS inhibitor L-NAME can lessen the accumulation of 3-NT in injured brains (Mesenge et al., 1998a) at the same doses which improve neurological recovery (Mesenge et al., 1996a). The current immunohistochemical results confirm those of others (Mesenge et al., 1998a,b), but more completely define the temporal and spatial characteristics of the post-traumatic increase in 3-NT in the injured mouse brain, including the fact that protein nitration and lipid peroxidation are largely coincident events, consistent with their induction by a common initiator, PON.

The fourth, and perhaps most compelling, line of evidence supporting a role of PON in acute TBI, comes from recent studies showing the neuroprotective properties of multiple compounds that possess the ability to directly scavenge PON or PON-derived radicals. For instance, it

\section{Stain intensity grading scale}
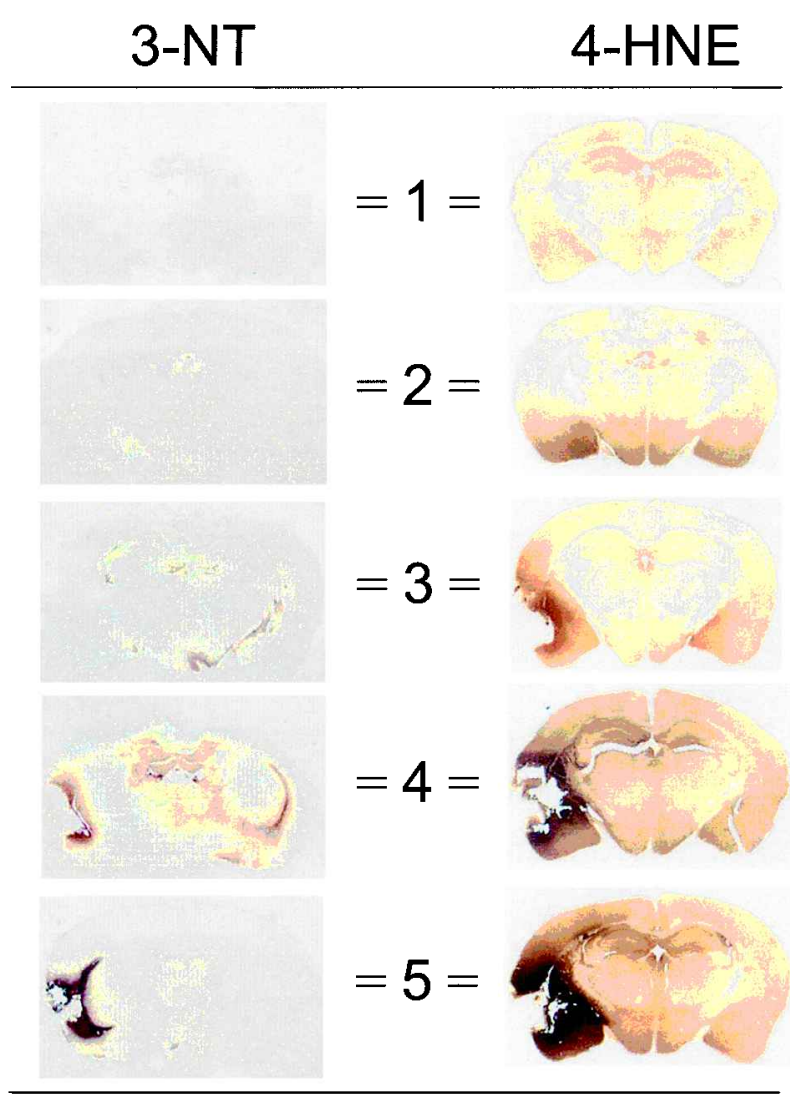

FIG. 5. Grading scale used for the semi-quantitative analysis of the post-traumatice time course of 3-NT and 4-HNE immunostaining. Staining was graded by intensity levels, where $1=$ very low (sham levels), $2=$ low, $3=$ medium, $4=$ medium high, and $5=$ high. 


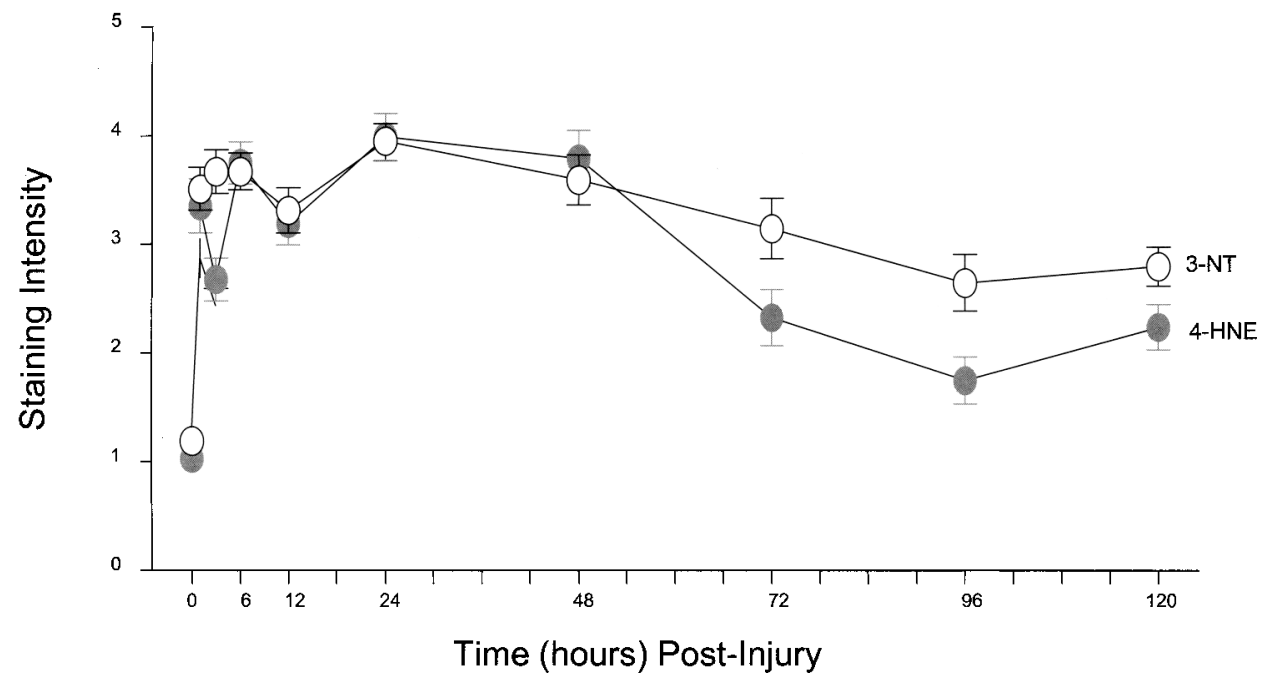

FIG. 6. Semi-quantitative analysis of post-traumatic oxidative damage (3-NT and 4-HNE). Points on the graph are (mean \pm SE) were derived from five graded brain sections from each of five mice. Therefore, a total of 25 sections, per time point, were evaluated for immunostaining intensity. The exceptions are at time-points 72 and $96 \mathrm{~h}$, where only four mice were evaluated (resulting in 20 sections per time point).

has been demonstrated that penicillamine, which can stoichiometrically react with PON (Althaus et al., 2000) is able to improve neurological recovery of mice subjected to moderately severe diffuse TBI (Hall et al., 1999). That study found that both the microvascularly-localized penicillamine and the brain-penetrable penicillamine methyl ester were effective in improving recovery, suggesting that PON is being generated within the brain microvasculature and parenchyma, consistent with the current finding of intense 3-NT immunostaining in both neurons and microvessels. Similarly, the brain-penetrable pyrrolopyrimidine antioxidant U-101033E, which can react with PON (Rohn et al., 1998), also improves the neurological recovery of injured mice (Hall et al., 1997). Furthermore, the indolamine melatonin (also reactive with PON) has been reported to be neuroprotective in mice after diffuse TBI (Mesenge et al., 1998b) and in rats after cortical contusion injury (Cirak et al., 1999; Sarrafzadeh et al., 2000). Thus far, the most promising anti-PON agent appears to be the antioxidant tempol, which has been shown to catalytically scavenge $\mathrm{PON}$-derived $\cdot \mathrm{NO}_{2}$ and $\cdot \mathrm{CO}_{3}$ (Carroll et al., 2000; Bonini et al., 2002). Tempol has been reported to reduce post-traumatic brain edema and improve neurological recovery in a rat focal contusion injury model (Beit-Yannai et al., 1996; Zhang et al., 1998). Furthermore, tempol has been shown to reduce ischemic brain damage in rodent models of focal (Rak et al., 2000) and global (Cuzzocrea et al., 2000) cerebral is- chemia and in a dog cardiac arrest paradigm (Behringer et al., 2002).

Despite the evidence in favor of PON as a principal initiator of oxidative damage and subsequent neurodegeneration in the injured brain, a careful comparison of the pattern of 4-HNE and 3-NT immunostaining shows that lipid peroxidation is more diffuse than protein nitration. This widespread LP is consistent with findings of others showing that even with focal contusions, LP-induced consumption of tissue antioxidants, although most intense in the peri-contusion area is also seen throughout the brain (Beit-Yannai et al., 1997). The most plausible explanation for this difference between 3-NT and 4-HNE (i.e., LP) staining pattern is that iron-dependent processes may contribute to lipid peroxidative brain damage in addition to PON (Hall and Braughler, 1993). In other words, while PON is clearly the source of 3-NT, the broader staining associated with 4-HNE may indicate that LP is being initated by both PON and iron-catalyzed mechanisms. Consistent with this hypothesis, compounds that block PON formation (i.e., NOS inhibitors) (Mesenge et al., 1996, 1998a; Wada et al., 1999), scavenge PON or PON-derived radicals (Beit-Yannai et al., 1996; Zhang et al., 1998; Hall et al., 1999), that chelate iron (Panter et al., 1992) or inhibit LP (Hall et al., 1988, 1994, 1997) are all effective in improving the neurological recovery of mice subjected to the presently employed diffuse injury. However, the present results suggest that the opti- 
mal pharmacological approach to inhibition of oxidative damage in TBI may be to simultaneously antagonize both PON and iron-dependent sources of neuronal and microvascular secondary injury. Accordingly, it has been shown that BN-80933, a compound that combines a neuronal NOS inhibitor with a trolox moiety (which scavenges lipid peroxyl radicals), more effectively improves neurological recovery in head-injured mice than when either moiety is given alone (Chabrier et al., 1999).

In conclusion, the current data demonstrate that the peak of oxidative damage to lipids and proteins precedes the timing of actual neurodegeneration, as determined by silver impregnation. Peroxynitrite and iron-dependent mechanisms are both involved. The concept that ROS, protein nitration and LP are mechanistically linked to neurodegeneration is based upon published reports showing the neuroprotective actions of ROS scavengers and LP inhibitors in TBI and related models (Hall et al., 1988; Awasthi et al., 1997; Hall, 1998). However, the exact linkage between oxidative damage processes and the actual process of neurodegeneration is not clear. Recent work by the authors has shown that calpain-mediated cytoskeletal damage temporally coincides with the timing of neurodegeneration (Kupina et al., 2003). Pathological calpain activation is known to be triggered by excessive intracellular calcium accumulation (Bartus, 1997; Kampfl et al., 1997). Thus, a likely explanation for how oxidative damage contributes to neurodegeneration is based upon the fact that ROS and LP are known to exacerbate glutamate release and glutamate receptor-coupled and voltage-dependent calcium conductances while at the same time compromising the neuronal homeostatic mechanisms that regulate glutamate release and intracellular calcium (e.g., $\mathrm{Ca}^{2+}$-ATPase, mitochondrial $\mathrm{Ca}^{++}$sequestration, $\mathrm{Na}^{+}, \mathrm{K}^{+}$-ATPase, $\mathrm{Na}^{+}-\mathrm{Ca}^{2+}$ exchanger) (Siesjo and Bengtsson, 1989; PellegriniGiampietro et al., 1990; Hall, 1995a; Sullivan et al., 1998). Thus, an ideal neuroprotective strategy may be to inhibit PON and iron-induced oxidative mechanisms together with, or followed by, inhibition of calpain-mediated cytoskeletal degradation.

\section{REFERENCES}

ALTHAUS, J.S., SCHMIDT, K.R., FOUNTAIN, S.T., et al. (2000). LC-MS/MS detection of peroxynitrite-derived 3-nitrotyrosine in rat microvessels. Free Radic. Biol. Med. 29, 1085-1095.

AWASTHI, D., CHURCH, D.F., TORBATI, D., et al. (1997). Oxidative stress following traumatic brain injury in rats. Surg. Neurol. 47, 575-581.
AZBILL, R.D., MU, X., BRUCE-KELLER, A.J., et al. (1997). Impaired mitochondrial function, oxidative stress and altered antioxidant enzyme activities following traumatic spinal cord injury. Brain Res. 765, 283-290.

BAO, F., and LIU, D. (2003). Peroxynitrite generated in the rat spinal cord induces apoptotic cell death and activates caspase-3. Neuroscience 116, 59-70.

BARTUS, R. (1997). The calpain hypothesis of neurodegeneration: evidence for a common cytotoxic pathway. The Neuroscientist 3, 314-327.

BECKMAN, J.S. (1991). The double-edged role of nitric oxide in brain function and superoxide-mediated injury. J. Dev. Physiol. 15, 53-59.

BECKMAN, J.S., CARSON, M., SMITH, C.D., et al. (1993). ALS, SOD and peroxynitrite. Nature 364, 584.

BEHRINGER, W., SAFAR, P., KENTNER, R., et al. (2002). Antioxidant Tempol enhances hypothermic cerebral preservation during prolonged cardiac arrest in dogs. PG-105-17. J. Cereb. Blood Flow Metab. 22, 105-117.

BEIT-YANNAI, E., KOHEN, R., HOROWITZ, M., et al. (1997). Changes in biological reducing activity in rat brain following closed head injury: a cyclic voltammetry study in normal and heat-acclimated rats. J. Cereb. Blood Flow Metab. 17, 273-279.

BEIT-YANNAI, E., ZHANG, R., TREMBOVLER, V., et al. (1996). Cerebroprotective effect of stable nitroxide radicals in closed head injury in the rat. Brain Res. 717, 22-28.

BONINI, M.G., MASON, R.P., and AUGUSTO, O. (2002). The Mechanism by which 4-hydroxy-2,2,6,6-tetramethylpiperidene-1-oxyl (tempol) diverts peroxynitrite decomposition from nitrating to nitrosating species. Chem. Res. Toxicol. 15, 506-511.

CARROLL, R.T., GALATSIS, P., BOROSKY, S., et al. (2000). 4-Hydroxy-2,2,6,6-tetramethylpiperidine-1-oxyl (Tempol) inhibits peroxynitrite-mediated phenol nitration. Chem. Res. Toxicol. 13, 294-300.

CHABRIER, P.E., AUGUET, M., SPINNEWYN, B., et al. (1999). BN 80933, a dual inhibitor of neuronal nitric oxide synthase and lipid peroxidation: a promising neuroprotective strategy. Proc. Natl. Acad. Sci. U.S.A. 96, 10824-10829.

CHAN, P.H., EPSTEIN, C.J., LI, Y., et al. (1995). Transgenic mice and knockout mutants in the study of oxidative stress in brain injury. J. Neurotrauma 12, 815-824.

CIRAK, B., ROUSAN, N., KOCAK, A., et al. (1999). Melatonin as a free radical scavenger in experimental head trauma. Pediatr. Neurosurg. 31, 298-301.

COBBS, C.S., FENOY, A., BREDT, D.S., et al. (1997). Expression of nitric oxide synthase in the cerebral microvasculature after traumatic brain injury in the rat. Brain Res. $\mathbf{7 5 1}$, 336-338. 
CUZZOCREA, S., McDONALD, M.C., MAZZON, E., et al. (2000). Effects of tempol, a membrane-permeable radical scavenger, in a gerbil model of brain injury. Brain Res. 875, 96-106.

DE OLMOS, J.S., BELTRAMINO, C.A., and DE OLMOS DE LORENZO, S. (1994). Use of an amino-cupric-silver technique for the detection of early and semiacute neuronal degeneration caused by neurotoxicants, hypoxia, and physical trauma. Neurotoxicol. Teratol. 16, 545-561.

GAHM, C., HOLMIN, S., and MATHIESEN, T. (2000). Temporal profiles and cellular sources of three nitric oxide synthase isoforms in the brain after experimental contusion. Neurosurgery 46, 169-177.

GAHM, C., HOLMIN, S., and MATHIESEN, T. (2002). Nitric oxide synthase expression after human brain contusion. Neurosurgery 50, 1319-1326.

GLOBUS, M.Y., ALONSO, O., DIETRICH, W.D., et al. (1995). Glutamate release and free radical production following brain injury: effects of posttraumatic hypothermia. $\mathbf{J}$. Neurochem. 65, 1704-1711.

GRAFE, M.R., and LEONARD, C.M. (1980). Successful silver impregnation of degenerating axons after long survivals in the human brain. J. Neuropathol. Exp. Neurol. 39, 555-574.

HALL, E.D. (1995a). Mechanisms of secondary CNS injury, in: Neurosurgery 96: Manual of Neurosurgery. J.D., Palmer (ed), Churchill-Livingstone: New York, pps. 505-510.

HALL, E.D. (1995b). The mouse head injury model: utility in the discovery of acute cerebroprotective agents, in: Central Nervous System Trauma Research Techniques. S.T. Ohnishi and T. Ohnishi (eds), CRC Press: Boca Raton, FL, pps. 213-233.

HALL, E.D. (1998). Antioxidant pharmacotherapy, in: Pathophysiology, Diagnosis, and Management. M.D. Ginsberg and J. Bogusslavsky (eds), Blackwell Science: Malden, MA, pps. 710-720.

HALL, E.D., ANDRUS, P.K., SMITH, S.L., et al. (1997). Pyrrolopyrimidines: novel brain-penetrating antioxidants with neuroprotective activity in brain injury and ischemia models. J. Pharmacol. Exp. Ther. 281, 895-904.

HALL, E.D., and BRAUGHLER, J.M. (1993). Free radicals in CNS injury. Res. Publ. Assoc. Res. Nerv. Ment. Dis. 71, 81-105.

HALL, E.D., KUPINA, N.C., and ALTHAUS, J.S. (1999). Peroxynitrite scavengers for the acute treatment of traumatic brain injury. Ann. NY Acad. Sci. 890, 462-468.

HALL, E.D., McCALL, J.M., and MEANS, E.D. (1994). Therapeutic potential of the lazaroids (21-aminosteroids) in acute central nervous system trauma, ischemia and subarachnoid hemorrhage. Adv. Pharmacol. 28, 221-268.

HALL, E.D., YONKERS, P.A., ANDRUS, P.K., et al. (1992).
Biochemistry and pharmacology of lipid antioxidantsin acute brain and spinal cord injury. PG-S425-42. J. Neurotrauma 9, (Suppl 2), S425-S442.

HALL, E.D., YONKERS, P.A., McCALL, J.M., et al. (1988). Effects of the 21-aminosteroid U74006F on experimental head injury in mice. J. Neurosurg. 68, 456-461.

KAMPFL, A., POSMANTUR, R. M., ZHAO, X., et al. (1997). Mechanisms of calpain proteolysis following traumatic brain injury: implications for pathology and therapy: implications for pathology and therapy: a review and update. J. Neurotrauma 14, 121-134.

KASPRZAK, H. A., WOZNIAK, A., DREWA, G., et al. (2001). Enhanced lipid peroxidation processes in patients after brain contusion. J. Neurotrauma 18, 793-797.

KONTOS, H. A. and POVLISHOCK, J. T. (1986). Oxygen radicals in brain injury. Cent. Nerv. Syst. Trauma 3, 257-263.

KONTOS, H. A. and WEI, E. P. (1986). Superoxide production in experimental brain injury. J. Neurosurg 64, 803-807.

KRUMAN, I., BRUCE-KELLER, A. J., BREDESEN, D., et al. (1997). Evidence that 4-hydroxynonenal mediates oxidative stress-induced neuronal apoptosis. J. Neurosci. 17, 50895100.

KUPINA, N., DETLOFF, M., BOBROWSKI, W., et al. (2003). Cytoskeletal protein degradation and neurodegeneration evolves differently in males and females following experimental head injury. Exp. Neurol. 180, 55-72.

KUPINA, N.C., DETLOFF, M., DUTTA, S., et al. (2002). The neuroimmunophilin ligand $\mathrm{V}-10,367$ is neuroprotective following 24-h delyaed administration in a mouse model of diffuse traumatic brain injury. J. Cereb. Blood Flow Metab. 22, 1212-1221.

KUPINA, N.C., NATH, R., BERNATH, E.E., et al. (2001). The novel calpain inhibitor SJA6017 improves functional outcome after delayed administration in a mouse model of diffuse brain injury. J. Neurotrauma 18, 1229-1240.

MARKLUND, N., CLAUSEN, F., LEWEN, A., et al. (2001). Alpha-penyl-tert- $N$-butyl nitrone (PBN) improves functional and morphological outcome after cortical contusion injury in the rat. Acta Neurochir. (Wien.) 143, 73-81.

MARSHALL, L.F., MAAS, A.I., and MARSHALL, S.B. (1998). A multicenter trial on the efficacy of using tirilazad mesylate in cases of head injury. J. Neurosurg. 89, 519-525.

MATSUSHITA, M., and XIONG, G. (1997). Projections from the cervical enlargement to the cerebellar nuclei in the rat, studied by anterograde axonal tracing. J. Comp. Neurol. 377, 251-261.

MESENGE, C., CHARRIAUT-MARLANGUE, C., VERRECCHIA, C., et al. (1998a). Reduction of tyrosine nitration after N(omega)-nitro-L-arginine-methylester treatment of mice with traumatic brain injury. Eur. J. Pharmacol. 353, 53-57. 
MESENGE, C., MARGAILl, I., VERRECCHIA, C., et al. (1998b). Protective effect of melatonin in a model of traumatic brain injury in mice. J. Pineal Res. 25, 41-46.

MESENGE, C., VERRECCHIA, C., ALLIX, M., et al. (1996). Reduction of the neurological deficit in mice with traumatic brain injury by nitric oxide synthase inhibitors. J. Neurotrauma 13, 209-214.

MIKAWA, S., KINOUCHI, H., KAMII, H., et al. (1996). Attenuation of acute and chronic damage following traumatic brain injury in copper, zinc-superoxide dismutase transgenic mice. J. Neurosurg. 85, 885-891.

MORI, T., KAWAMATA, T., KATAYAMA, Y., et al. (1998). Antioxidant, OPC-14117, attenuates edema formation, and subsequent tissue damage following cortical contusion in rats. Acta Neurochir. Suppl. (Wien.) 71, 120-122.

NEELY, M. D., SIDELL, K. R., GRAHAM, D. G., et al. (1999). The lipid peroxidation product 4-hydroxynonenal inhibits neurite outgrowth, disrupts neuronal microtubules, and modifies cellular tubulin. J. Neurochem. 72, 23232333.

NISHIO, S., YUNOKI, M., NOGUCHI, Y., et al. (1997). Detection of lipid peroxidation and hydroxyl radicals in brain contusion of rats. Acta Neurochir. Suppl. (Wien.) 70, 84-86.

ORIHARA, Y., IKEMATSU, K., TSUDA, R., et al. (2001). Induction of nitric oxide synthase by traumatic brain injury. Forensic Sci. Int. 123, 142-149.

PANTER, S. S., BRAUGHLER, J. M. and HALL, E. D. (1992). Dextran-coupled deferoxamine improves outcome in a murine model of head injury. J. Neurotrauma 9, 47-53.

PARK, C. O. and YI, H. G. (2001). Apoptotic change and NOS activity in the experimental animal diffuse axonal injury model. Yonsei Med. J. 42, 518-526.

PELlEGRINI-GIAMPIETRO, D. E., CHERICI, G., ALESIANI, M., et al. (1990). Excitatory amino acid release and free radical formation may cooperate in the genesis of ischemia-induced neuronal damage. J. Neurosci. 10, 10351041 .

PETROV, T., PAGE, A. B., OWEN, C. R., et al. (2000). Expression of the inducible nitric oxide synthase in distinct cellular types after traumatic brain injury: an in situ hybridization and immunocytochemical study. Acta Neuropathol. (Berl.) 100, 196-204.

RAK, R., CHAO, D. L., PLUTA, R. M., et al. (2000). Neuroprotection by the stable nitroxide Tempol during reperfusion in a rat model of transient focal ischemia. PG-646-51. J. Neurosurg. 92, 646-651.

RAO, V. L., DOGAN, A., BOWEN, K. K., et al. (1999). Traumatic injury to rat brain upregulates neuronal nitric oxide synthase expression and L-[3H]nitroargininebinding. J. Neurotrauma 16, 865-877.
ROHN, T. T., NELSON, L. K., WAEG, G., et al. (1998). U101033E (2,4-diaminopyrrolopyrimidine), a potent inhibitor of membrane lipid peroxidation as assessed by the production of 4-hydroxynonenal, malondialdehyde, and 4-hydroxynonenal-protein adducts. Biochem. Pharmacol. 56, 1371-1379.

SARRAFZADEH, A. S., THOMALE, U. W., KROPPENSTEDT, S. N., et al. (2000). Neuroprotective effect of melatonin on cortical impact injury in the rat. Acta Neurochir. (Wien.) 142, 1293-1299.

SIESJO, B. K. and BENGTSSON, F. (1989). Calcium fluxes, calcium antagonists, and calcium-related pathology in brain ischemia, hypoglycemia, and spreading depression: a unifying hypothesis. J. Cereb. Blood Flow Metab. 9, 127-140.

SILBERSTEIN, M., LANE, D., DODD, S., et al. (2002). Identification of a by-product of nitric oxide synthase activity in human acute brain injury with in vivo proton magnetic resonance spectroscopy. Am. J. Neuroradiol. 23, 389-392.

SMITH, S. L., ANDRUS, P. K., ZHANG, J. R., et al. (1994). Direct measurement of hydroxyl radicals, lipid peroxidation, and blood-brain barrier disruption following unilateral cortical impact head injury in the rat. $\underline{\text { J. Neurotrauma }}$ 11, 393-404.

SULLIVAN, P. G., BRUCE-KELLER, A. J., RABCHEVSKY, A. G., et al. (1999a). Exacerbation of damage and altered NFkappaB activation in mice lacking tumor necrosis factor receptors after traumatic brain injury. J. Neurosci. 19, 6248-6256.

SUllivan, P. G., KELlER, J. N., MATTSON, M. P., et al. (1998). Traumatic brain injury alters synaptic homeostasis: implications for impaired mitochondrial and transport function. J. Neurotrauma 15, 789-798.

SULLIVAN, P. G., THOMPSON, M. B. and SCHEFF, S. W. (1999b). Cyclosporin A attenuates acute mitochondrial dysfunction following traumatic brain injury. Exp. Neurol. 160, $226-234$.

SWITZER, R. C., III. (2000). Application of silver degeneration stains for neurotoxicity testing. Toxicol. Pathol. 28, 70-83.

UCHIDA, K. and STADTMAN, E. R. (1993). Covalent attachment of 4-hydroxynonenal to glyceraldehyde-3-phosphate dehydrogenase. A possible involvement of intra- and intermolecular cross-linking reaction. J. Biol. Chem. 268, 6388-6393.

WADA, K., CHATZIPANTELI, K., BUSTO, R., et al. (1998a). Role of nitric oxide in traumatic brain injury in the rat. $\underline{\mathrm{J}}$. Neurosurg. 89, 807-818.

WADA, K., CHATZIPANTELI, K., BUSTO, R., et al. (1999). Effects of L-NAME and 7-NI on NOS catalytic activity and behavioral outcome after traumatic brain injury in the rat. $\underline{\mathbf{J}}$. Neurotrauma 16, 203-212.

WADA, K., CHATZIPANTELI, K., KRAYDIEH, S., et al. (1998b). Inducible nitric oxide synthase expression after trau- 
HALL ET AL.

matic brain injury and neuroprotection with aminoguanidine treatment in rats. Neurosurgery 43, 1427-1436.

YAMAMOTO, T., IWASAKI, Y., KONNO, H., et al. (1986). Identification of cells undergoing physiological neuronal death in the neonatal rat brain by the Fink-Heimer method. Brain Res. 374, 419-424.

ZHANG, R., SHOHAMI, E., BEIT-YANNAI, E., et al. (1998). Mechanism of brain protection by nitroxide radicals in experimental model of closed-head injury. Free Radic. Biol. Med. 24, 332-340.
Address reprint requests to:

Edward D. Hall, Ph.D.

Spinal Cord \& Brain Injury Research Center University of Kentucky Chandler Medical Center

232 Health Sciences Research Building 800 Rose Street Lexington, $K Y$ 40536-0305

E-mail: edhall@uky.edu 


\section{This article has been cited by:}

1. Valerie C Besson. 2009. Drug targets for traumatic brain injury from poly(ADP-ribose)polymerase pathway modulation. British Journal of Pharmacology 157:5, 695-704. [CrossRef]

2.Xiang Gao , Jinhui Chen . Conditional Knockout of Brain-Derived Neurotrophic Factor in the Hippocampus Increases Death of Adult-Born Immature Neurons following Traumatic Brain InjuryConditional Knockout of Brain-Derived Neurotrophic Factor in the Hippocampus Increases Death of Adult-Born Immature Neurons following Traumatic Brain Injury. Journal of Neurotrauma, ahead of print. [Abstract] [PDF] [PDF Plus]

3. Kyoko Tsuru-Aoyagi, Matthew B. Potts, Alpa Trivedi, Timothy Pfankuch, Jacob Raber, Michael Wendland, Catherine P. Claus, Seong-Eun Koh, Donna Ferriero, Linda J. Noble-Haeusslein. 2009. Glutathione peroxidase activity modulates recovery in the injured immature brain. Annals of Neurology 65:5, 540-549. [CrossRef]

4. Ms. Kimberly M Carrico, Dr. Radhika A Vaishnav, Dr. Edward D Hall . Temporal and Spatial Dynamics of Peroxynitrite-Induced Oxidative Damage After Spinal Cord Contusion InjuryTemporal and Spatial Dynamics of Peroxynitrite-Induced Oxidative Damage After Spinal Cord Contusion Injury. Journal of Neurotrauma 0:ja. . [Abstract] [PDF] [PDF Plus]

5. Tanea T. Reed, Joshua Owen, William M. Pierce, Andrea Sebastian, Patrick G. Sullivan, D. Allan Butterfield. 2009. Proteomic identification of nitrated brain proteins in traumatic brain-injured rats treated postinjury with gamma-glutamylcysteine ethyl ester: Insights into the role of elevation of glutathione as a potential therapeutic strategy for traumatic brain injury. Journal of Neuroscience Research 87:2, 408-417. [CrossRef]

6. Dr. Xiang Gao , Dr. Jinhui Chen . Conditional knockout of brain-derived neurotrophic factor in the hippocampus increases death of adult-born immature neurons following traumatic brain injuryConditional knockout of brain-derived neurotrophic factor in the hippocampus increases death of adult-born immature neurons following traumatic brain injury. Journal of Neurotrauma 0:ja. . [Abstract] [PDF] [PDF Plus]

7. Marcela A Avila, Stacy L Sell, Yuji Kadoi, Donald S Prough, Helen L Hellmich, Marco Velasco, Douglas S Dewitt. 2008. L-Arginine decreases fluid-percussion injury-induced neuronal nitrotyrosine immunoreactivity in rats. Journal of Cerebral Blood Flow \&\#38; Metabolism 28:10, 1733-1741. [CrossRef]

8. Jimmi Hatton, Bonnie Rosbolt, Philip Empey, Richard Kryscio, Byron Young. 2008. Dosing and safety of cyclosporine in patients with severe brain injury. Journal of Neurosurgery 109:4, 699-707. [CrossRef]

9. Xiang Gao, Ying Deng-Bryant, Wongil Cho, Kimberly M. Carrico, Edward D. Hall, Jinhui Chen. 2008. Selective death of newborn neurons in hippocampal dentate gyrus following moderate experimental traumatic brain injury. Journal of Neuroscience Research 86:10, 2258-2270. [CrossRef]

10. Indrapal N. Singh, Edward D. Hall. 2008. Multifaceted roles of sphingosine-1-phosphate: How does this bioactive sphingolipid fit with acute neurological injury?. Journal of Neuroscience Research 86:7, 1419-1433. [CrossRef]

11. Edward D. Hall, Ying Deng Bryant, Wongil Cho , Patrick G. Sullivan . 2008. Evolution of Post-Traumatic Neurodegeneration after Controlled Cortical Impact Traumatic Brain Injury in Mice and Rats as Assessed by the De Olmos Silver and Fluorojade Staining MethodsEvolution of Post-Traumatic Neurodegeneration after Controlled Cortical Impact Traumatic Brain Injury in Mice and Rats as Assessed by the De Olmos Silver and Fluorojade Staining Methods. Journal of Neurotrauma 25:3, 235-247. [Abstract] [PDF] [PDF Plus]

12. Edward S. Ahn, Courtney L. Robertson, Viktoria Vereczki, Gloria E. Hoffman, Gary Fiskum. 2008. Normoxic ventilatory resuscitation following controlled cortical impact reduces peroxynitrite-mediated protein nitration in the hippocampus. Journal of Neurosurgery 108:1, 124-131. [CrossRef]

13. Joshua R Dusick, Thomas C Glenn, W N Paul Lee, Paul M Vespa, Daniel F Kelly, Stefan M Lee, David A Hovda, Neil A Martin. 2007. Increased pentose phosphate pathway flux after clinical traumatic brain 
injury: a [1,2-13C2]glucose labeling study in humans. Journal of Cerebral Blood Flow \&\#38; Metabolism 27:9, 1593-1602. [CrossRef]

14. Hülya Bayir, Vladimir A. Tyurin, Yulia Y. Tyurina, Rosa Viner, Vladimir Ritov, Andrew A. Amoscato, Qing Zhao, Xiaojing J. Zhang, Keri L. Janesko-Feldman, Henry Alexander, Liana V. Basova, Robert S. B. Clark, Patrick M. Kochanek, Valerian E. Kagan. 2007. Selective early cardiolipin peroxidation after traumatic brain injury: an oxidative lipidomics analysis. Annals of Neurology 62:2, 154-169. [CrossRef]

15. Indrapal N. Singh, Patrick G. Sullivan, Edward D. Hall. 2007. Peroxynitrite-mediated oxidative damage to brain mitochondria: Protective effects of peroxynitrite scavengers. Journal of Neuroscience Research 85:10, 2216-2223. [CrossRef]

16. Barbara Tavazzi, Roberto Vagnozzi, Stefano Signoretti, Angela M. Amorini, Antonino Finocchiaro, Marco Cimatti, Roberto Delfini, Valentina Di Pietro, Antonio Belli, Giuseppe Lazzarino. 2007. TEMPORAL WINDOW OF METABOLIC BRAIN VULNERABILITY TO CONCUSSIONS. Neurosurgery 61:2, 390-396. [CrossRef]

17. Knox Van Dyke, Erica Ghareeb, Mark Van Dyke, David H. Van Thiel. 2007. Ultrasensitive peroxynitrite-based luminescence with $\mathrm{L}-012$ as a screening system for antioxidative/antinitrating substances, e.g. Tylenol ${ }^{\circledR}$ (acetaminophen), 4-OH tempol, quercetin and carboxy-PTIO. Luminescence 22:4, 267-274. [CrossRef]

18. Xiao Ru Chen, Valerie C. Besson , Bruno Palmier, Yannick Garcia, Michel Plotkine, Catherine Marchand-Leroux . 2007. Neurological Recovery-Promoting, Anti-Inflammatory, and Anti-Oxidative Effects Afforded by Fenofibrate, a PPAR Alpha Agonist, in Traumatic Brain InjuryNeurological Recovery-Promoting, Anti-Inflammatory, and Anti-Oxidative Effects Afforded by Fenofibrate, a PPAR Alpha Agonist, in Traumatic Brain Injury. Journal of Neurotrauma 24:7, 1119-1131. [Abstract] [PDF] [PDF Plus]

19. Brenda L. Bartnik, Stefan M. Lee, David A. Hovda, Richard L. Sutton . 2007. The Fate of Glucose during the Period of Decreased Metabolism after Fluid Percussion Injury: A 13C NMR StudyThe Fate of Glucose during the Period of Decreased Metabolism after Fluid Percussion Injury: A 13C NMR Study. Journal of Neurotrauma 24:7, 1079-1092. [Abstract] [PDF] [PDF Plus]

20. Hülya Bayır, Valerian E. Kagan, Robert S. B. Clark, Keri Janesko-Feldman, Ruslan Rafikov, Zhentai Huang, Xiaojing Zhang, Vincent Vagni, Timothy R. Billiar, Patrick M. Kochanek. 2007. Neuronal NOS-mediated nitration and inactivation of manganese superoxide dismutase in brain after experimental and human brain injury. Journal of Neurochemistry 101:1, 168-181. [CrossRef]

21. H T Chang. 2007. Subacute human spinal cord contusion: few lymphocytes and many macrophages. Spinal Cord 45:2, 174-182. [CrossRef]

22. Jorge E. Hachmeister, Lokanatha Valluru, Feng Bao, Danxia Liu . 2006. Mn (III) Tetrakis (4-Benzoic Acid) Porphyrin Administered into the Intrathecal Space Reduces Oxidative Damage and Neuron Death after Spinal Cord Injury: A Comparison with MethylprednisoloneMn (III) Tetrakis (4-Benzoic Acid) Porphyrin Administered into the Intrathecal Space Reduces Oxidative Damage and Neuron Death after Spinal Cord Injury: A Comparison with Methylprednisolone. Journal of Neurotrauma 23:12, 1766-1778. [Abstract] [PDF] [PDF Plus]

23. Viktoria Vereczki, Erica Martin, Robert E Rosenthal, Patrick R Hof, Gloria E Hoffman, Gary Fiskum. 2006. Normoxic resuscitation after cardiac arrest protects against hippocampal oxidative stress, metabolic dysfunction, and neuronal death. Journal of Cerebral Blood Flow \&\#38; Metabolism 26:6, 821-835. [CrossRef]

24. Amedeo Merenda, Ross Bullock. 2006. Clinical treatments for mitochondrial dysfunctions after brain injury. Current Opinion in Critical Care 12:2, 90???96. [CrossRef]

25. Courtney L. Robertson, Lucian Soane, Zachary T. Siegel, Gary Fiskum. 2006. The Potential Role of Mitochondria in Pediatric Traumatic Brain Injury. Developmental Neuroscience 28:4-5, 432-446. [CrossRef] 
26. H\&uuml;lya Bay\&inodot;r, Patrick M. Kochanek, Valerian E. Kagan. 2006. Oxidative Stress in Immature Brain after Traumatic Brain Injury. Developmental Neuroscience 28:4-5, 420-431. [CrossRef]

27. Caroline Gahm, Alexandre Danilov, Staffan Holmin, Peter N. Wiklund, Lou Brundin, Tiit Mathiesen. 2006. Reduced Neuronal Injury after Treatment with NG-nitro-L-arginine methyl ester (L-NAME) or 2-sulfo-phenyl-N-tert-butyl nitrone (S-PBN) Following Experimental Brain Contusion. Neurosurgery 1272-1281. [CrossRef]

28. Danxia Liu , Feng Bao , Donald S. Prough , Douglas S. DeWitt . 2005. Peroxynitrite Generated at the Level Produced by Spinal Cord Injury Induces Peroxidation of Membrane Phospholipids in Normal Rat Cord: Reduction by a MetalloporphyrinPeroxynitrite Generated at the Level Produced by Spinal Cord Injury Induces Peroxidation of Membrane Phospholipids in Normal Rat Cord: Reduction by a Metalloporphyrin. Journal of Neurotrauma 22:10, 1123-1133. [Abstract] [PDF] [PDF Plus]

29. Brenda L. Bartnik, Richard L. Sutton, Masamichi Fukushima , Neil G. Harris, David A. Hovda , Stefan M. Lee . 2005. Upregulation of Pentose Phosphate Pathway and Preservation of Tricarboxylic Acid Cycle Flux after Experimental Brain InjuryUpregulation of Pentose Phosphate Pathway and Preservation of Tricarboxylic Acid Cycle Flux after Experimental Brain Injury. Journal of Neurotrauma 22:10, 1052-1065. [Abstract] [PDF] [PDF Plus]

30. Hülya Bayır, Valerian E Kagan, Grigory G Borisenko, Yulia Y Tyurina, Keri L Janesko, Vincent A Vagni, Timothy R Billiar, Deborah L Williams, Patrick M Kochanek. 2005. Enhanced oxidative stress in iNOS-deficient mice after traumatic brain injury: support for a neuroprotective role of iNOS. Journal of Cerebral Blood Flow \&\#38; Metabolism 25:6, 673-684. [CrossRef]

31. Edward D. Hall , Tonya R. Gibson , Kristina M. Pavel . 2005. Lack of a Gender Difference in Post-Traumatic Neurodegeneration in the Mouse Controlled Cortical Impact Injury ModelLack of a Gender Difference in Post-Traumatic Neurodegeneration in the Mouse Controlled Cortical Impact Injury Model. Journal of Neurotrauma 22:6, 669-679. [Abstract] [PDF] [PDF Plus]

32. Edward D. Hall, Patrick G. Sullivan, Tonya R. Gibson, Krissi M. Pavel, Brian M. Thompson, Stephen W. Scheff . 2005. Spatial and Temporal Characteristics of Neurodegeneration after Controlled Cortical Impact in Mice: More than a Focal Brain InjurySpatial and Temporal Characteristics of Neurodegeneration after Controlled Cortical Impact in Mice: More than a Focal Brain Injury. Journal of Neurotrauma 22:2, 252-265. [Abstract] [PDF] [PDF Plus] 